\title{
On the true optical properties of zinc nitride
}

\author{
C. García Núñez, ${ }^{\text {a) }}$ J. L. Pau, M. J. Hernández, M. Cervera, and J. Piqueras \\ Laboratorio de Microelectrónica, Dpto. de Física Aplicada, Universidad Autónoma de Madrid, \\ c/Fco. Tomás y Valiente 7, Madrid 28049, Spain
}

(Received 12 July 2011; accepted 27 October 2011; published online 8 December 2011)

\begin{abstract}
Refractive index ( $n)$ and extinction coefficient $(k)$ of $\mathrm{Zn}_{3} \mathrm{~N}_{2}$ layers deposited by radio-frequency magnetron sputtering at temperatures $\left(T_{\mathrm{s}}\right)$ between 298 and $523 \mathrm{~K}$ were determined by spectroscopic ellipsometry. Results showed strong variations of the apparent optical constants with $T_{\mathrm{s}}$ and time attributed to surface effects. Resonant Rutherford backscattering and spectroscopic ellipsometry confirmed the formation of a $\mathrm{ZnO}$ surface layer provoked by the ambient exposure. Samples grown at low $T_{s}$ presented the lowest surface roughness and exhibited $2.0<n<2.8$ and $0.6<k<1.0$ in the $1.5-4.5 \mathrm{eV}$ energy range. The extracted $n$ and $k$ values accurately reproduced the reflectance properties. (C) 2011 American Institute of Physics. [doi:10.1063/1.3663859]
\end{abstract}

Zinc nitride $\left(\mathrm{Zn}_{3} \mathrm{~N}_{2}\right)$ is a promising material for application in electronics and optoelectronics due to its high electron mobility and conductivity. Electrical studies in $\mathrm{Zn}_{3} \mathrm{~N}_{2}$ showed similar mobility and resistivity values to those obtained in poly-Si (at the same carrier concentration) and even better than in a-Si. ${ }^{1}$ Moreover, the low cost of its elements and synthesis procedure makes $\mathrm{Zn}_{3} \mathrm{~N}_{2}$ an excellent choice for mass production in electronic systems. Thus, $\mathrm{Zn}_{3} \mathrm{~N}_{2}$ is recognized as a potential substitute of $\mathrm{Si}$ for the fabrication of thin film transistors along with other materials such as graphene or $\mathrm{ZnO}$. Furthermore, it has been demonstrated the possibility of transforming $\mathrm{Zn}_{3} \mathrm{~N}_{2}$ into p-type $\mathrm{ZnO}$ by thermal treatment in oxidizing ambient, which enables the fabrication of $\mathrm{ZnO}$ p-n homojunctions for the development of ultraviolet light emitters. ${ }^{2}$

However, an issue related to this material is its tendency to oxidize in ambient conditions, which hinders its optical and electrical characterizations. Indeed, its true bandgap energy is still a matter of controversy and values between 1.01 (Ref. 3) and $3.4 \mathrm{eV}$ (Ref. 4) have been reported. Although bandgap variations have been attributed to the formation of defects and the Moss-Burstein effect, such a wide range is unusual in other semiconductors. Several works have shown degradation of the $\mathrm{Zn}_{3} \mathrm{~N}_{2}$ surface due to the ambient exposure. ${ }^{5}$ The oxygen content varied depending on the surface properties, as found by means of surface analysis techniques such as Auger electron spectroscopy and x-ray photoelectron spectroscopy. Although optical constants have been determined in the past, ${ }^{1,6}$ the impact of surface effects such as surface roughness or the formation of native oxide on the calculated parameters has not been discussed yet. Therefore, it is important to analyze the changes introduced by those on the apparent optical characteristics of the $\mathrm{Zn}_{3} \mathrm{~N}_{2}$ films. Ellipsometry is an effective tool to rapidly detect morphology and chemical modification of materials over time. ${ }^{7}$ This work provides insight on the relationship between surface effects and the optical properties of $\mathrm{Zn}_{3} \mathrm{~N}_{2}$ layers using resonant Rutherford backscattering (RBS), scanning electron

\footnotetext{
a) Author to whom correspondence should be addressed. Electronic mail: carlos.garcia@uam.es.
}

microscopy (SEM), spectroscopic ellipsometry (SE), and reflectance spectroscopy (RS). SE was used to determine the optical constants, i.e., refractive index $(n)$ and extinction coefficient $(k)$, of zinc nitride layers and RS helped to confirm their values.

$\mathrm{Zn}_{3} \mathrm{~N}_{2}$ layers were prepared from a pure $\mathrm{Zn}(99.995 \%)$ plasma sputtered target using $\mathrm{N}_{2}(99.999 \%$ purity) as working gas. $\mathrm{N}_{2}$ gas was introduced through a mass flow controller. To study the effect of growth temperature $\left(T_{\mathrm{s}}\right)$, five samples were synthesized at $T_{\mathrm{s}}$ between 298 and $523 \mathrm{~K}$ on $\mathrm{Si}(100)$ and glass substrates keeping a constant chamber pressure of $1 \mathrm{~Pa}$ by adjusting the pumping rate with a throttle valve. The $\mathrm{N}_{2}$ total gas flow was set at $30 \mathrm{sccm}$. Layer thicknesses ranged from 0.19 to $2.2 \mu \mathrm{m}$, as determined using a stylus profiler.

Prior to deposition, the growth chamber was evacuated below $10^{-4} \mathrm{~Pa}$ with a turbo-molecular pump. After that, $\mathrm{Si}(100)$ substrates were chemically treated with HF to remove $\mathrm{SiO}_{2}$ cap-layer, whereas glass substrates were rinsed up using ethanol. Right before each growth, both types of substrates and also the target were sputtered with Ar during $5 \mathrm{~min}$ to avoid unintentional surface impurities.

The surface morphology of the $\mathrm{Zn}_{3} \mathrm{~N}_{2}$ samples was examined by SEM using a Philips XL30 microscope at $20-\mathrm{kV}$ operation voltage.

SE was carried out in order to determine the optical parameters of the nitride films. The ellipsometry system allowed obtaining $\Psi$ and $\Delta$ quantities of the layers as a function of the photon energy in the $1.5-4.5 \mathrm{eV}$ range. Both magnitudes were used to calculate $n$ and $k$ through the dielectric functions $\left(\varepsilon_{\mathrm{r}}\right.$ and $\left.\varepsilon_{\mathrm{i}}\right){ }^{8}$ In the experiment setup, the angle of incidence $(\theta)$ was set at $70^{\circ}$ which corresponds to the Brewster angle of the $\mathrm{Si}$ substrate. Reflectance measurements were performed at normal incidence using a UV/Vis/NIR spectrophotometer in the energy range from 1.5 to $4.5 \mathrm{eV}$.

Resonant RBS measurements performed at the Center of Microanalysis of Materials (CMAM/UAM) enabled calculation of the stoichiometries and thicknesses of the $\mathrm{Zn}_{3} \mathrm{~N}_{2}$ layers through the use of the data fitting software SIMNRA. Composition and thicknesses of $\mathrm{ZnO}$ layers unintentionally formed atop the nitride layers after air exposure were also 


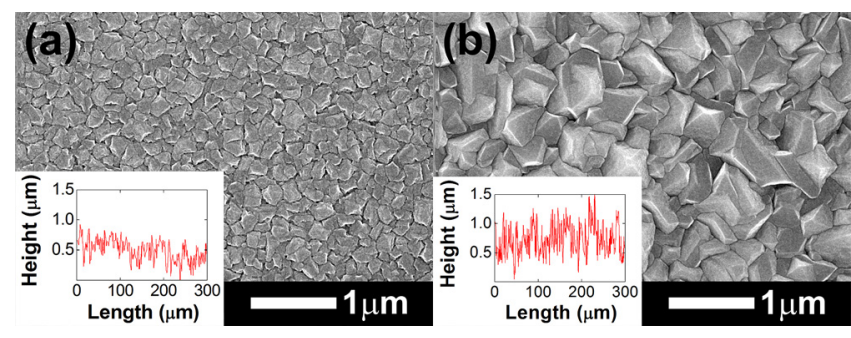

FIG. 1. (Color online) SEM images of $\mathrm{Zn}_{3} \mathrm{~N}_{2}$ samples grown at (a) 298 and (b) $473 \mathrm{~K}$. Inset: linear scan obtained with the stylus profilometer.

analyzed. Resonant RBS studies were performed using alpha particles at energies of 3.045 and $3.7 \mathrm{MeV}$ to enhance backscattered signals from $\mathrm{O}$ and $\mathrm{N}$, respectively, through their atomic resonances. The backscattered ions were detected by a standard Si-barrier detector located at an angle of $170^{\circ}$ to the beam direction. The energy calibration of the detector was $2.62 \mathrm{keV} /$ channel with an energy offset around $114 \mathrm{keV}$.

Figure 1 shows SEM images of two nitride layers grown at 298 and 473-K deposition temperatures. The resultant layers showed lower grain sizes and a smoother surface morphology at low growth temperatures. A linear scan using the stylus profiler also revealed a more irregular surface for $T_{\mathrm{s}}=473 \mathrm{~K}$ (insets, Figure 1). The morphology of the nitride film grown at $298 \mathrm{~K}$ was reanalyzed after 1 week in ambient conditions. Results suggested that surface roughness increased over time.

SE was performed above the $\mathrm{Zn}_{3} \mathrm{~N}_{2}$ energy bandgap $(E>1.5 \mathrm{eV})$. As shown in Figure 2, obtained $\Psi$ and $\Delta$ values were strongly dependent on $T_{\mathrm{s}}$. In general, $\Psi$ increased and $\Delta$ decreased with the photon energy. At high $T_{\mathrm{s}}(423-523 \mathrm{~K})$, $\Psi$ and $\Delta$ values were significantly higher and lower, respectively, than those obtained at low $T_{\mathrm{s}}(298-373 \mathrm{~K})$. The differences between the results at low and high $T_{\mathrm{s}}$ were attributed to the effect of surface roughness. To further investigate this

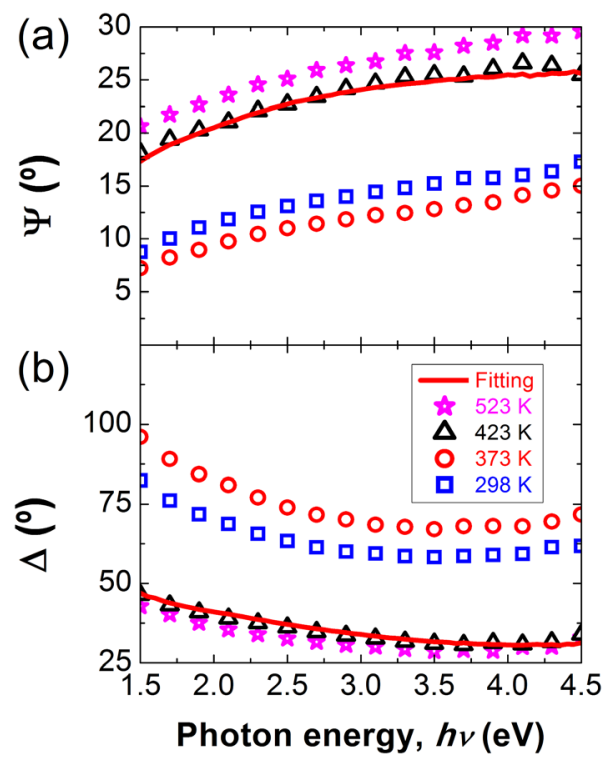

FIG. 2. (Color online) (a) $\Psi$ and (b) $\Delta$ of layers grown at different $T_{s}$ vs. photon energy. Lines represent the fitting curves of the three-phase model. point, a model comprising three $\mathrm{Zn}_{3} \mathrm{~N}_{2}$ phases with different void densities was used to fit the results at high temperatures and, thus, to simulate the surface roughness effect. The bottom nitride phase was considered homogeneous, compact, and semi-infinite and its $\Psi$ and $\Delta$ values are those obtained at $373 \mathrm{~K}$. The other two nitride phases on top of this used the same $\Psi$ and $\Delta$ values and had void densities introduced using the Bruggeman effective medium approximation (EMA), ${ }^{9}$ trying to account for the surface roughness effect on the layers grown at high temperatures. Experimental values for both magnitudes $\Psi$ and $\Delta$ were used to calculate $\varepsilon_{\mathrm{r}}$ and $\varepsilon_{\mathrm{i}}$ through

$$
\varepsilon_{r}+j \varepsilon_{i}=\sin ^{2} \theta+\sin ^{2} \theta \tan ^{2} \theta\left(\frac{1+\rho}{1-\rho}\right)^{2},
$$

where $\rho$ depends on the ellipsometric angles as $\rho=\tan \Psi e^{j \Delta}$. The dielectric functions were fitted using the three-phase model, through an iterative process in which thickness and void density were varied. The best fitting (minimum chisquare error, $\chi^{2}=0.03$ ) of the $423 \mathrm{~K}$ values was achieved using the following $\mathrm{Zn}_{3} \mathrm{~N}_{2}$ phases from top to bottom: 1) a 48-nm thick layer with $50 \%$ void density, and 2) a 220-nm thick layer with $30 \%$ void density. Lines in Figure 2 represent the fitting curves to the experimental data for $T_{\mathrm{s}}=423 \mathrm{~K}$. The good agreement with the data confirms that surface roughness accounts well for the variation of the ellipsometric angles at high $T_{\mathrm{s}}$.

A study about the effect of surface oxidation on the ellipsometric properties was also performed by remeasuring the sample grown at $298 \mathrm{~K}$ for 1 week after its growth. The results had considerably changed presenting characteristic interference oscillations (Figure 3) below $3.2 \mathrm{eV}$ which were attributed to the multiple internal reflections between the film and a transparent top layer. ${ }^{10}$ As the maximum energy at which those oscillations show up matches, the $\mathrm{ZnO}$ energy bandgap is believed that they are produced by the ex-situ formation of an oxide surface layer. A three-phase model was also used in order to corroborate this belief. In this model, the bottom phase consisted of a homogeneous, compact, and semi-infinite $\mathrm{Zn}_{3} \mathrm{~N}_{2}$ phase with optical constants equal to those obtained right after the growth. The two phases atop this were made of $\mathrm{ZnO}^{11}$ with different void densities and thicknesses. Figure 3 showed the results of the fitting $\left(\chi^{2}=0.07\right)$ using the following $\mathrm{ZnO}$ phases from top to bottom: 1) a $50-\mathrm{nm}$ thick layer with $60 \%$ void density, and 2) a

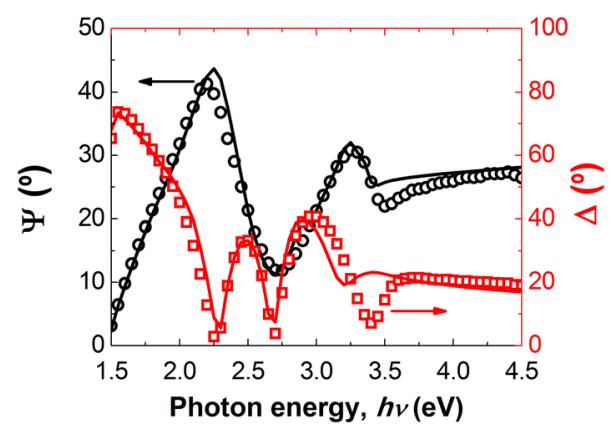

FIG. 3. (Color online) Experimental data of $\mathrm{Zn}_{3} \mathrm{~N}_{2}$ layer grown at $298 \mathrm{~K}$ with 1 week in ambient, and fitting curves of the three-phase model. 


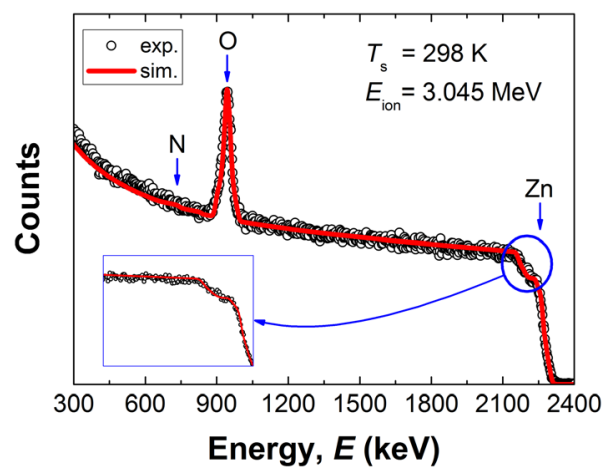

FIG. 4. (Color online) Film grown at $298 \mathrm{~K}$ after 1 week in air exposure. The inset points out the stoichiometry changes near the surface.

250 -nm thick layer with $40 \%$ void density. The model reproduces well the observed oscillatory behavior below the bandgap and confirms the presence of an oxide layer. In fact, it was observed that long exposure times produced a complete transformation of the nitride into oxide phase. Moreover, if this layer is not taken into account during optical characterization of the nitride, it could lead to overestimate the bandgap energy.

The formation of surface $\mathrm{ZnO}$ was also corroborated by resonant RBS measurements. The thickness of those layers increased over time. It was also found that, at high $T_{\mathrm{s}}$, nitride layers were more stable to the oxidation effect. After 1 week, the oxide layer was easily detectable in the RBS spectrum (Figure 4) for a $\mathrm{Zn}_{3} \mathrm{~N}_{2}$ film grown at $298 \mathrm{~K}$ on $\mathrm{Si}(100)$ through the reduction in the height of the $\mathrm{Zn}$ signal near the surface, which confirms the transformation of $\mathrm{Zn}_{3} \mathrm{~N}_{2}$ into $\mathrm{ZnO}$. The reduction of the signal has its origin in the different atomic concentration of both compounds $(60 \%$ and $50 \%$, respectively). The thickness of the oxide layer was $10^{18}$ atoms $/ \mathrm{cm}^{2}$ whereas the nitride layer was $2 \times 10^{19}$-atoms $/ \mathrm{cm}^{2}$ thick. Therefore, the RBS study supports the use of a model with $\mathrm{ZnO}$ atop $\mathrm{Zn}_{3} \mathrm{~N}_{2}$ in the ellipsometric analysis.

Taking this study into account, it is concluded that the surface roughness and oxidation are responsible of the differences in the optical properties. The optical constants were calculated in the $373-\mathrm{K}$ sample by using $\varepsilon_{r}+j \varepsilon_{i}=(n+j k)^{2}$

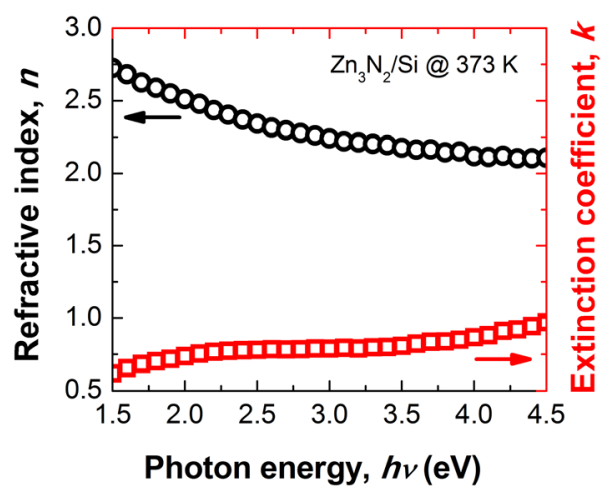

FIG. 5. (Color online) Optical constants of $\mathrm{Zn}_{3} \mathrm{~N}_{2}$ film grown at $373 \mathrm{~K}$ as a function of the photon energy.

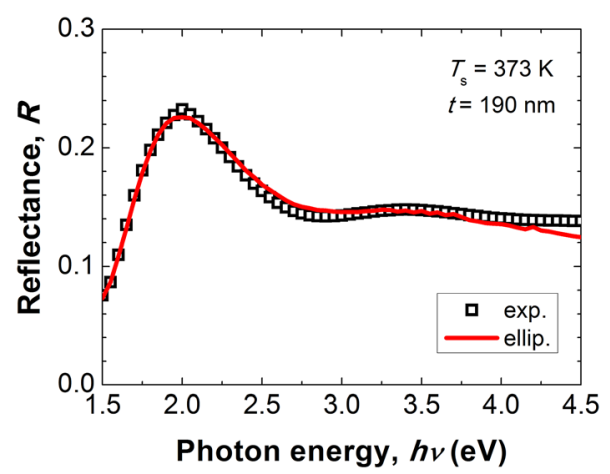

FIG. 6. (Color online) Squares: reflectance measured in a film grown at $373 \mathrm{~K}$; line: reflectance calculated from the $n$ and $k$ values.

(Figure 5). In comparison to the rest, this sample yields a maximum $n$ value due to its lower surface roughness. For that reason, the $n$ and $k$ values are considered the most realistic ones among all the samples tested.

Finally, following Heavens, ${ }^{12} R$ coefficient was calculated using the $n$ and $k$ values obtained by SE for a $190-\mathrm{nm}$ thick layer grown at $373 \mathrm{~K}$. The calculation was compared to the experimental reflectance (see Figure 6), both showing a good agreement, even without taking into account the film roughness in Heavens' formulae due to the better surface properties of films grown at low $T_{\mathrm{s}}$.

$\mathrm{Zn}_{3} \mathrm{~N}_{2}$ layers prepared by rf-magnetron sputtering were morphologically, optically, and compositionally characterized by means of SEM, SE, RS, and resonant RBS. SE has demonstrated to be an effective tool to identify $n=2.8-2.0$ and $k=0.6-1.0$ as the optical constants of zinc nitride for photon energies between 1.5 and $4.5 \mathrm{eV}$, and the formation of native $\mathrm{ZnO}$ on top of the nitride layer after air exposure.

This research is partially supported by the Comunidad de Madrid R+D S2009/PPQ-1642 and TEC2010-20796 projects.

${ }^{1}$ T. Suda and K. Kakishita, J. Appl. Phys. 99, 076101 (2006).

${ }^{2}$ W. Lim, E. A. Douglas, D. P. Norton, S. J. Pearton, F. Ren, Y. -W. Heo, S. Y. Son, and J. H. Yun, Appl. Phys. Lett. 96, 053510 (2010).

${ }^{3}$ K. Toyoura, H. Tsujimura, T. Goto, K. Hachiya, R. Hagiwara, and Y. Ito, Thin Solid Films 492, 88 (2005).

${ }^{4}$ V. Kambilafka, P. Voulgaropoulou, S. Dounis, E. Iliopoulos, M. Androulidaki, V. Sály, M. Ruzinský, and E. Aperathitis, Superlattices Microstruct. 42, 55 (2007).

${ }^{5}$ M. Futsuhara, K. Yoshioka, and O. Takai, Thin Solid Films 322, 274 (1998).

${ }^{6}$ R. Ayouchi, C. Casteleiro, L. Santos, and R. Schwarz, Phys. Status Solidi 9, 2294 (2010).

${ }^{7}$ F. J. Nelson, V. K. Kamineni, T. Zhang, E. S. Comfort, J. U. Lee, and A. C. Diebold, Appl. Phys. Lett. 97, 253110 (2010).

${ }^{8} \mathrm{H}$. G. Tompkins, A User's Guide to Ellipsometry (Academic, London, 1993).

${ }^{9}$ D. A. G. Bruggeman, Ann. Phys. 24, 636 (1935).

${ }^{10}$ P. L. Washington, H. C. Ong, J. Y. Dai, and R. P. H. Chang, Appl. Phys. Lett. 72, 3261 (1998).

${ }^{11} \mathrm{H}$. Landolt, R. Börnstein, Numerical Data and Functional Relationships in Science and Technology, edited by W. Martienssen (Springer, Berlin 2009).

${ }^{12}$ O. S. Heavens, Optical properties of Thin Solid Films (Butterworth, London, 1955). 